\title{
Plants at risk from climate change
}

\section{Chris Yesson \& Alastair Culham School of Biological Sciences}

The popular garden flower Cyclamen grows natively in the Mediterranean. Climate change could make the region unsuitable for eighteen out of twenty-one species in $\mathbf{5 0}$ years time. Ant-dispersed Cyclamen can't hope to migrate to suitable new areas without human intervention. This pattern of change and loss could be typical for European plant species.

\section{Background}

The impact of global climate change on plant distribution, speciation and extinction is of current concern. Examining species climatic preferences via bioclimatic niche modelling is a established link between bioclimatic niche models and phylogentic diversification. A next models and phylogenetic diversification. A next step is to from an phy predictions from a phylogenetic perspective. We present such a study using Cyclamen (Myrsinaceae), a group which demonstrates morphological and phenological adaptations to its seasonal Mediteranean-type climate. How will the predicted climate change affect future plants?

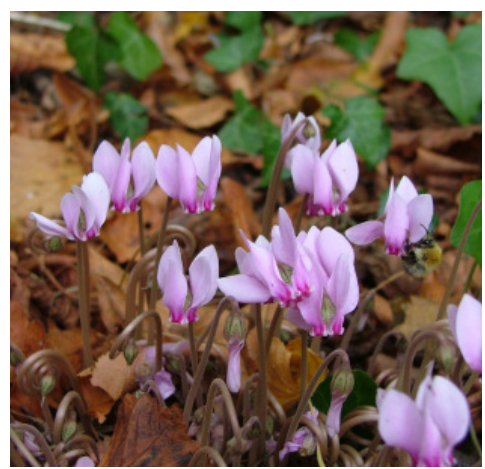

C. hederifolium naturalised in the UK.

Photo: A. Culham

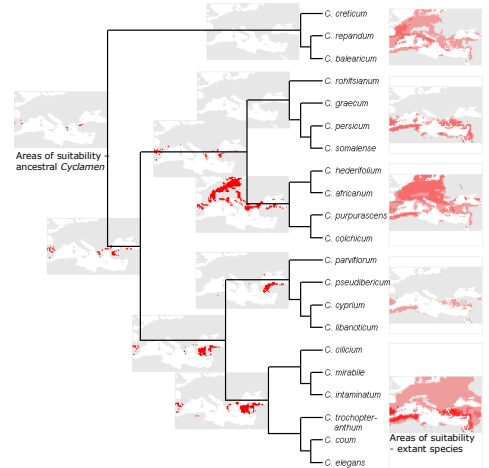

Fig 1: Ancestral reconstru

\section{References}

Phylogeny from Compton, J.A. et al. (2004) Bot.J. Lin. Soc. 146: 339-349

Distribution data from Grey-Wilson, C. (2003). Cyclamen: a guide for gardeners... Batsford, London.

Poster adapted from Yesson, C. \& Culham, A. (2006) BMC Evolutionary Biology 6:72

Acknowledgments

Thanks to Peter Brewer, Chloe Lee, Sue Rumsey, Tim Sutton, Nicola Toomey, The Cyclamen Society (http://www.cyclamen.org/) Media Interest

Daily Mail, Telegraph, Mirror, BBC Radio 4 The Leading Edge \& Gardeners' Question Time Awards

Highly commended at 2006 BioMedcentral Biology Awards

\section{Results}

We demonstrate phylogenetic patterns for some climatic characteristics, and show that most Cyclamen have distinct climatic niches, with the exception of several wideranging, geographically expansive, species. We reconstruct climate preferences for hypothetical ancestral Cyclamen (fig 1). The ancestral Cyclamen lineage has a preference for the seasonal Mediterranean climate characteristic of dry summers and wet winters. Future bioclimatic niches, based on BIOCLIM models, are examined with ce climate scenario for the 2050s (fig 283). Over the next 50 years we predict a northward shift in the area of climatic suitability, with many areas of current distribution becoming climatically unsuitable. The area of climatic suitability for every Cyclamen species is predicted to decrease. For many species, there may be 作 considered to be at high risk of extinction. This isk is examined from a phylogenetic perspective (fig 4).

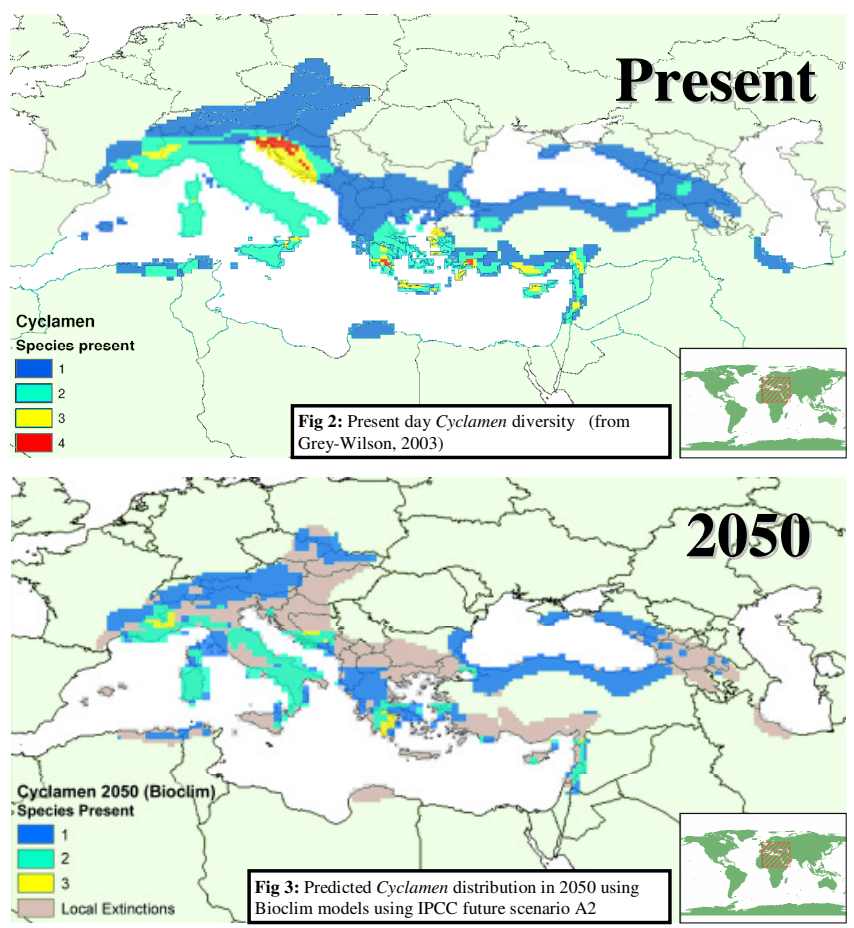

\section{Conclusions}

Examining bioclimatic niches from a phylogenetic perspective permits nove interpretations of these models. In particular, reconstruction of ancestral niches can provide testable hypothesis about the historical development of lineages. In the future we can expect a northwards shift in climatic suitability for the genus Cyclamen. If this proves to be the case then dispersal is the best chance of survival which seems highly unlikely for ant-dispersed Cyclamen. Human-assisted establishment of Cyclamen species well outside their native ranges offers hope and could provide the only means of dispersal to potentially suitable future environments. Even without human intervention the phylogenetic perspective demonstrates that major lineages could survive climate change even if many species are lost.

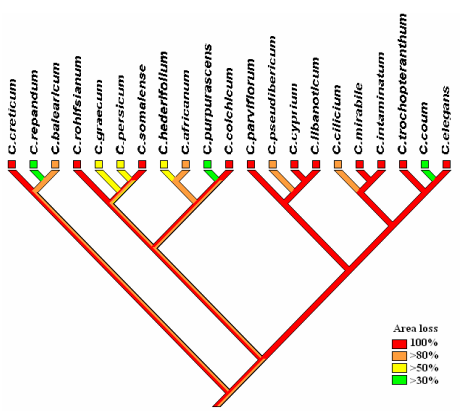

Fig 4: Extinction risk in Cyclamen, a phylogenetic

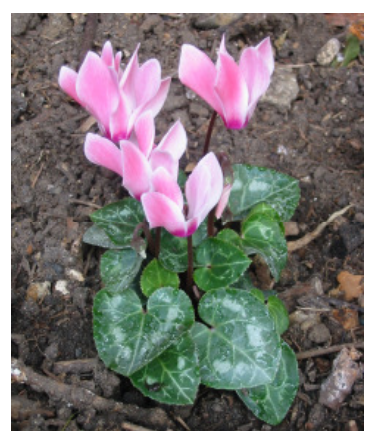

A modern garden cultivar of C. persicum 